and unnecessary surgery" is no greater than that in any other branch of surgery.

P G MCANDREW Consultant maxillofacial surgeo Rotherham District General Hospital,

Rotherham S60 2UD

1 Shepherd JP, Brickley M. Surgical removal of third molars. $B M F$ 1994;309:620-1. (10 September.)

\section{Authors' reply}

EDrToR,-Although no consensus was reached concerning prophylactic removal of third molars at the National Institutes of Health Conference in 1979 , the decision and cost-benefit analyses published since have concluded that this is not an appropriate strategy. ${ }^{1}$ Longitudinal studies show that the prevalence of disease associated with third molars peaks at ages $18-25^{1}$ and that impacted third molars that are free of disease in middle aged people can be safely left in situ because disease rarely develops and is usually minor when it does. A substantial number of impacted third molars erupt, given the chance. ${ }^{3}$ Malpositioned third molars are often valued by restorative dentists in the construction of bridges, dentures, and overdentures for older people.

Assessments by oral surgeons ${ }^{1}$ and potential patients ${ }^{4}$ of health states (utilities) resulting from surgical intervention and non-intervention, when subjected to formal decision analysis, have shown that the best treatment strategy in relation to teeth that are free of disease is non-intervention. Dentists in teaching hospitals feel the same way about their own third molars. ${ }^{5}$ Theoretically, given accurate prediction about the development of virtually any disease, prophylactic surgical excision is best carried out when someone is young and fit. Unfortunately, in practice and given current knowledge, this prediction cannot be made for third molars, even when teeth are impacted.

"Free of disease" is a much better term than "asymptomatic" since follicular cysts and periodontal disease are often asymptomatic.

Clinical guidelines should be explicit about the circumstances in which removal of third molars in the absence of local disease may be justified-for example, in surgery for jaw deformity or when there is a risk of endocarditis. Evidence currently available, however, supports the view that prophylactic removal (of teeth that are free of disease) should be carried out only in exceptional, wel defined circumstances. The same applies to exceptions to the general guidance that third molars should be removed on a day case or outpatient basis.

The findings of the audit in Trent reported by P G McAndrew are similar to those of the audit in Bristol cited in our editorial. In Trent consultants found that disease justifying surgical removal was absent in 76 of 275 patients, but only 17 patients were not scheduled for surgery. Russell Hopkins draws attention to important, unresolved questions. We welcomed the national third molar survey when it was initiated and look forward to seeing the results.

JONATHAN SHEPHERD Professor of oral and maxillofacial surgery MARK R BRICKLEY

University of Wales College of Medicine, Research fellow

\section{Cardiff CF4 4XY}

1 Toth B. The appropriateness of prophylactic extraction of impacted third molars. Bristol: Healthcare Evaluation Unit, University of Bristol, 1993.

2 Ahlqwist M, Grondahl II G. Prevalence of impacted teeth and associated pathology in middle-aged and older Swedish and associated pathology in middle-aged and older

3 Von Wowern N, Nielsen HO. The fate of impacted lower third molars after the age of 20 . A five year clinical follow up Int 7 Oral Maxillofac Surg 1989;18:277-80.

4 Brickley MR, Kay EJ, Shepherd JP. A decision making analysi of lower third molar surgery. Med Decis Making 1993;13:381.

5 Brickley MR, Heald H, Shepherd JP. Third molar wisdom Br Dent f 1990;169:314.

\section{Each case needs careful thought}

EDrToR,-Jonathan $\mathbf{P}$ Shepherd and Mark Brickley's editorial looks at the arguments for abandoning the prophylactic removal of impacted or unerupted third molars but does not explain the historical reasons why this has been traditional practice.' For these we must go back to the days before penicillin. Sulphonamides were not particularly effective in treating serious odontogenic infections. Consequently, cellulitis spreading into the tissues from pericoronitis around impacted lower third molars and massive, dangerous abscesses involving the adjacent tissue spaces were common and their treatment far from satisfactory. If an impacted tooth had been affected by several episodes of pericoronitis the timing of its removal was crucial. Even then, osteomyelitis spreading from an infected socket was a distinct risk. These were the cogent reasons why, at that time, patients were advised to have their impacted but not infected third molars removed. All such problems have declined dramatically in the intervening years but have not entirely disappeared.

A further consideration was that surgery becomes increasingly difficult with advancing age. Before the mid-20s a tooth, once disimpacted, is easily dislodged from the socket. After this age a greater effort is required to disrupt the attachment. From middle age onwards the bone of the jaw becomes progressively harder and more brittle so that in elderly people the greater part of the socket may have to be removed before the tooth will move without a fracture. Until relatively recently most people were edentulous by their old age, and unerupted teeth emerged and became infected under their dentures. With the increasing hazards of anaesthetics and surgery with age the earlier removal, even of buried teeth, was a sensible policy, and for some patients it still is.

As Shepherd and Brickley point out, times have changed and the morbidity associated with removal of third molars now usually outweighs any advantage of prophylactic surgery. Nevertheless, mesioangular and horizontal teeth can still lead to caries low down on the neck of the second molar, where it can affect the pulp before becoming clinically detectable.

Treatment habits are ripe for further change but not as a matter of policy, nor should prophylactic surgery be totally abandoned. Each case necessitates careful thought and discussion with the patient, who should be well informed-not least because our patients will grow older and the full consequences of some of our decisions are still to come.

G R SEWARD

Hadley Wood,

Barnet,

Hertfordshire EN4 OLU

1 Shepherd JP, Brickley M. Surgical removal of third molars. BMf 1994;309:620-1. (10 September.)

\section{Early mortality after dental operations}

\section{What constitutes a dental operation?}

EDITOR,-Valerie Seagroatt and Michael Goldacre propose that an almost doubled standardised mortality ratio during the year after dental operations may be explained by the fact that they studied patients receiving inpatient rather than outpatient treatment, who by definition would have a greater risk of postoperative complications. ${ }^{\prime}$ The explanation may, however, be far simpler and may lie in the authors' ambiguous use of the term "dental operations." If the term means, as most people would understand it without further explanation, dentoalveolar surgery then their results are surprising. If, however, the term refers to the full range of dental, oral, and maxillofacial surgery then such a high mortality ratio could be more easily explained: an appreciable proportion of patients admitted for oral and maxillofacial surgery will be suffering from oral, perioral, and salivary gland malignancy, which in itself carries a considerable risk of death.

It is unfortunate that Seagroatt and Goldacre do not give examples of specific dental operations, as they do with other operations, given that without further clarification their statistics are alarmingperhaps unnecessarily.

PETER S G F HARDEE

Whittington Hospital, Surgical senior house office

London N195N

1 Seagroatt V, Goldacre $M$. Measures of early postoperative mortality: beyond hospital fatality rates. $B M \mathcal{F}$ 1994;309:361-6. (6 August.)

\section{Authors' reply}

EDrTor,-The dental operations were those recorded as codes 251 and 252- "simple dental extraction" and "surgical extraction of tooth"-in the third revision of the Office of Population Censuses and Surveys' classification of surgical operations (as we specified in table I in our paper). As we also specified, we excluded patients for whom a diagnosis of cancer had been recorded at admission. We therefore think that our results are unlikely to have been influenced by an appreciable proportion of patients having been admitted for oral and maxillofacial conditions that themselves carry a considerable risk of death.

Our aim was to quantify and attempt to interpret any short term mortality after operation by identifying, in particular, whether operations were followed by clustering of deaths shortly afterwards. We did not find a significant short term clustering of deaths after the dental operations. We found that the standardised mortality ratio for this group of patients was generally higher than the population average throughout the year.

We doubt that this is attributable in any way to the operations. We think that it is much more likely to be an effect of selection-that is, that the population that underwent dental operations was (in aggregate) slightly less healthy than the general population. One possibility, as we speculated, is that this may reflect the kind of patients who undergo these operations on an inpatient rather than an ambulatory basis. Another is that, more generally, some patients who require dental operations may be less healthy than average. If our explanation is correct-that the increased standardised mortality ratio thoughout the post operative year in this group of patients is attributable to the characteristics of the patients rather than to the operations they undergo-the findings are not alarming in respect of the risk of dental surgery.

VALERIE SEAGROATT Statistician MICHAEL GOLDACRE

Unit of Health Care Epidemiology, Department of Public Health and Primary Care, University of Oxford, Oxford OX3 7LF 1 Office of Population Censuses and Surveys. Classification of
surgical operations, 3rd revision. London: OPCS, 1975.

\section{Future of preventive dentistry}

EDITOR,-Aubrey Sheiham presents an interesting picture of dentistry in Britain today, but his view that we could do with fewer dentists and less treatment is one sided. ${ }^{1}$ At present, the demand for dental services is still higher than the supply in 
areas away from centres of population in the south east of England. The Netherlands, which shared Sheiham's philosophy and closed all but one of its dental schools, is now reopening two despite having one of the lowest levels of dental caries in the world.

Seaton suggests that dentists should do fewer fillings, but the number of restorations in each course of treatment carried out in the General Dental Services has reduced in line with the prevalence of dental caries. ${ }^{2}$ Evidence exists that, far from patients being overtreated, a degree of undertreatment exists, especially in the young age groups. ${ }^{3}$ Seaton also omits to say that the number of teeth in people's mouths is increasing at a remarkable rate owing to an aging population which is keeping its teeth rather than having them removed. ${ }^{4}$ This increasing pool of teeth is being maintained with difficult and complex restorative procedures that modern dentistry is offering to enthusiastic patients. ${ }^{1}$ Although demand by patients for these procedures may reduce in future generations, at present these treatments are making an important contribution to people's oral wellbeing, which the government should not ignore. ${ }^{5}$

Seaton also brings forth the hoary old topic of the six monthly recall. It is now well established in dental teaching that patients should be recalled at intervals that are governed by their own dental health needs; intervals may vary from three months for patients with advanced periodontal disease to two years for those whose dental health is sound and stable. Finally, Seaton suggests a population strategy for the continued prevention of dental disease and cites the expansion of fluoridated water and political strategies for the reduction of sugar consumption. Although the theoretical benefits of these two options are undeniable, the cause of fluoridation has been pursued avidly in many parts of the country since the fluoridation act of 1985 without a single success, and the return from an effort to reduce sugar intake in the population is of questionable cost-benefit. ${ }^{6}$ Until the population strategy is shown to be effective it would be folly to decrease Britain's dentist-population ratio, which remains one of the lowest in Europe.

ANTHONY S BLINKHORN Professor of dental health PJ HOLLOWAY Emeritus professo N H F WILSON

Turner Dental School, University Dental Hospital of Manchester, Manchester M15 6FH

1 Sheiham A. The future of preventive dentistry. BMF 1994;309: 214. (23 July.)

2 Dental Practice Board. Annual reports 1980-1993. Brighton: DPB, 1981-94.

3 Office of Population Censuses and Surveys. Dental caries among children in the United Kingdom in 1993. London: OPCS, 1994. children in the United
(OPCS Monitor.)

4 Todd JE, Lader D. Adult dental health 1988 United Kingdom London: HMSO, 1991

5 Improving NHS dentistry: government green paper. London: HMSO, 1994.

6 Burt BA, Szpunar SM. The Michigan study: the relationship between sugars intake and dental caries over three years. Int Dent f 1994;44:230-40.

\section{Children's consent to treatment}

EdrToR,-William G Brooks Jr and colleagues oppose the practice of requesting children's consent to treatment on four grounds. ${ }^{1}$ They believe that this would "trivialise" the process of obtaining consent, would add a "cumbersome legal manoeuvre," and is "inappropriate and impractical." Similar objections used to be raised with regard to the consent of adult patients, but they are now discredited in the United States and Britain. Brooks and colleagues cite research showing that many adults do not understand consent forms, but they miss the point that the difficulty frequently lies not in the inability of adults to grasp the salient issues but in the inability of doctors to write clear forms.

There is growing research evidence that, in the view of the adults caring for them, certain young children are capable of understanding complex and distressing information. Children want to be informed, and many wish to share in making decisions about their health treatment. ${ }^{2}$ The law in Britain respects the decisions of competent children. The medical profession expects decisions about clinical treatment to be based on evidence rather than opinion; should not the same standard apply to decisions about the social and ethical treatment of patients? Brooks and colleagues' letter seems to endorse unjust double standards regarding the treatment of adults and that of competent children. Do the authors advocate that treatment should be enforced on uninformed or resisting competent children?

ocial Science Research Unit

PRISCILLA ALDERSON

Social Science Research

University of London, London WC1H ONS

1 Brooks WG Jr, Bahar-Posey L, Weathers LS, Pardue W. Children's Jr, Bant-Posey L, Children's cons

2 Alderson P. Children's consent to surgery. Buckingham: Open University Press, 1993.

\section{Coronary heart disease in women}

\section{Women may be more ill when they reach hospital}

EDITOR,-Three papers in the issue of 3 September follow the recent publication of findings in 38 populations worldwide from the World Health Organisation's MONICA project (to monitor the trends in and determinants of cardiovascular diseases). ${ }^{4}$ Our comparison from the Scottish MONICA project in Glasgow from 1985 to 1991 of 3991 myocardial infarctions and coronary deaths in men with 1551 in women (aged 25-64) gives an added perspective.

The international study (which used standardised criteria monitored from Dundee) shows a negative correlation in women, but not men, between population event rates and case fatality at 28 days. Case fatality among women is highest where coronary disease is uncommon, and nonfatal cases in women may be being missed, but is similar to that among men where coronary event rates are high. ${ }^{4}$ However, this report (besides incidentally redefining the alleged French paradox $^{56}$ as common to southern Europe) also shows a difference between the sexes in how suddenly and where deaths occur, which is well illustrated by our findings in Glasgow.

In Glasgow 1989 (49.8\%) coronary episodes ended in death by 28 days in men compared with $770(49.7 \%)$ in women, and $1830(45.9 \%)$ men and $687(44.3 \%)$ women were treated in coronary care units. These percentages differ little, yet 2568 $(64.3 \%)$ men reached hospital alive versus 1059 $(68 \cdot 2 \%)$ women. Therefore among the patients treated in hospital, $71.3 \%$ of men were treated by coronary care compared with $64.9 \%$ of women, which suggests possible bias. The clinical presentation in women, however, was slightly different: fewer had electrocardiographic $Q$ wave progression (more having lesser electrocardiographic findings with raised cardiac enzymes); more had shock, syncope, and left ventricular failure; and more satisfied the criteria of the WHO MONICA project (coded by our female registration team) for atypical as against typical symptoms. ${ }^{4}$ These factors may have affected the emergency treatment and the wards to which patients were admitted.

Thus there seem to be sex differences in presentation. Compared with men, a greater proportion of women arriving at hospital are more ill and with less readily diagnosed disease and die; a greater proportion of men die suddenly without reaching hospital. Survival at 28 days, on the basis of the definitions used in the WHO MONICA project, ${ }^{4}$ seems to be the same. Current follow up in the WHO MONICA project stops at 28 days, but we plan to study survival further by record linkage.

HUGH TUNSTALL-PEDOE Principal investigator, Scottish MONICA Project Cardiovascular Epidemiology Unit,

University of Dundee,

Ninewells Hospital,

Dundee DD1 9SY

Coprincipalinvestigator

Glasgow MONICA Project,

Glasgow Royal Infirmary,

Glasgow G31 2ER

1 Clarke KW, Gray D, Keating NA, Hampton JR. Do women with acute myocardial infarction receive the same treatment as men? BMF 1994;309:563-6. (3 September.)

2 Wilkinson $\mathrm{P}$, Laii $\mathrm{K}$, Ranjadayalan $\mathrm{K}$, Parsons $\mathrm{L}$, Timmis AD. Acute myocardial infarction in women: survival analysis in first six months. BMf 1994;309:566-9. (3 September.)

3 Hannaford PC, Kay CR, Parry S. Agism as explanation for sexism in provision of thrombolysis. BMF 1994;309:573-4. (3
s. sexism in provis
September.)

WHO MONICA Project, prepared by Tunstall-Pedoe $\mathrm{H}_{2}$ Kuulasmaa K, Amouyel P, Arveiler D, Rajakangas A-M, Pajak A. Myocardial infarction and coronary deaths in the World Health Organization MONICA project; registration procedures, event rates and case fatality rates in 38 populations from 21 countries in four continents. Circulation 1994;90: 583-612.

5 Smith T. French mysteries. BMF 1994;309:277. (23 July.)

6 Briggs JC. Coronary heart disease in France. BMf 1994;309:611. (3 September.)

\section{Adjustment for age changes results}

EdToR,-Paul Wilkinson and colleagues report that women have a poorer prognosis after an acute myocardial infarction than men and that the difference in the proportion who survive to six months is around $15 \% .^{1}$ The information and statistics division of the NHS in Scotland has made data available to the Public Health Research Unit, which has permitted examination of the survival of all Scottish patients admitted to NHS hospitals in Scotland in 1989 with a diagnosis of acute myocardial infarction (International Classification of Diseases code 410).

The data consist of hospital discharge summaries and death certificates, which have been linked together for each patient. Each hospital discharge summary includes the sex and age of the patient as well as the date of admission to hospital and diagnosis. The linkage was performed by the medical record linkage team at the information and statistics division. In 1989, 11225 people (6974 men, 4251 women) aged $40-79$ were admitted to hospital with a main diagnosis of acute myocardial infarction. This age group made up $88 \%$ of all the men and $74 \%$ of all the women admitted with myocardial infarction during the year. The age distributions of the men and women differed, with $695(10.0 \%)$ men and $159(3.7 \%)$ women being aged $40-49,1809(25.9 \%)$ and $662(15.6 \%)$ respectively aged 50-59, $2570(36.9 \%)$ and $1479(34.8 \%)$ aged 60-69, and $1900(27 \cdot 2 \%)$ and 1951 (45.9\%) aged 70-79.

Survival analysis of the time from first admission in 1989 to death from all causes within two years was carried out with the log rank test. When no adjustment was made for differences in age between the men and women survival curves similar to those reported by Wilkinson and colleagues were found. When adjustment was made for age, however, this difference disappeared (figure; stratified log rank test, $P>0 \cdot 44$ ). Similar 